Nevşehir Bilim ve Teknoloji Dergisi Cilt 6(1) 10-19 2017

DOI: 10.17100/nevbiltek.331407

URL: http://dx.doi.org/10.17100/nevbiltek.331407

\title{
Trifluralin,Treflan ve Etil Metan Sülfonatın Oreochromis niloticus’ta Oluşturduğu Genotoksik Hasar Üzerine Askorbik Asitin Antigenotoksik Etkisi
}

\author{
Serpil Könen-Adıgüzel ${ }^{1, *}$, Tolga Çavaş ${ }^{2}$ \\ ${ }^{1}$ Mersin Üniversitesi, Fen Edebiyat Fakültesi, Biyoloji Bölümü, Mersin. \\ ${ }^{2}$ Uludağ Üniversitesi, Fen Edebiyat Fakültesi, Biyoloji Bölümü, Bursa.
}

Öz

Bu çalışmada askorbik asitin (vitamin C) muhtemel antigenotoksik etkisi, ticari değeri olan balık türü Oreochromis niloticus (Nile Tilapia)'un eritrositlerinde mikronukleus ve nuklear anomali testleri kullanılarak değerlendirilmiştir. Balıklar; herbisit etken maddesi trifluralin ve ticari formu treflanın (litrede $480 \mathrm{gr}$ trifluralin ve ticari olarak özel bileşenler) genotoksik konsantrasyonlarına $(10 \mu \mathrm{g} / \mathrm{L})$, pozitif kontrol olarak etil metan sülfonata (EMS) $(10 \mathrm{mg} / \mathrm{L}) 6$ gün boyunca maruz bırakılmıştır. Trifluralin, treflan ve etil metan sülfonat konsantrasyonları, içerisinde 10 litre musluk suyu bulunan 30x20x15cm ebatlarındaki akvaryumlara eklenmiştir. Musluk suyu negatif kontrol olarak kullanılmıştır. Askorbik asit (\%0.05) balıklara intraperitonal olarak maruziyetin 1 . ve 3. günlerinde $0.1 \mathrm{ml} / 10 \mathrm{~g}$ vücut ağırlığı olacak şekilde uygulanmıştır. Askorbik asitin herbisitlerin oluşturduğu genotoksik hasarı düzenleyici etkisi mikronukleus ve nuklear anomali testi ile değerlendirilmiştir. Analiz sonuçları; trifluralin, treflan ve etil metan sülfonat uygulamalarının balık eritrositlerinde genotoksik hasarı yükselttiğini göstermiştir. Ancak, kimyasallarla kombine şekilde askorbik asit uygulaması hasarlı hücre oranını önemli derecede azaltmıştır. Sonuç olarak, askorbik asit herbisitler tarafindan oluşturulan genotoksik hasara karşı koruyucu etki göstermiştir. $\mathrm{Bu}$ nedenle balık çiftliklerinde genotoksik hasarın önlenmesi/azaltılması amacıyla yemlerde askorbik asit kullanılabilir.

Anahtar Kelimeler: Antigenotoksik, askorbik asit, mikronukleus, Oreochromis niloticus, Trifluralin.

\section{Antigenotoxic Effect of Ascorbic Acid on Genotoxic Damage in Oreochromis niloticus Induced by Trifluralin, Treflan and Ethyl Methane Sulfonate}

\begin{abstract}
In this study, possible anti-genotoxic effect of ascorbic acid (vitamin C) was investigated by micronucleus and nuclear abnormality test in peripheral erythrocytes of a commercially important fish species, Oreochromis niloticus, (Nile Tilapia). The fish were exposed to genotoxic concentrations of trifluralin $(10 \mu \mathrm{g} / \mathrm{L})$, and its commercial form, Treflan (10 $\mu \mathrm{g} / \mathrm{L}$, composition: trifluralin 480 $\mathrm{g} / \mathrm{L}$ and commercially-confidential components) and ethyl methane sulfonate (EMS) (as a positive control, $10 \mathrm{mg} / \mathrm{L}$ ) for 6 days. Trifluralin, treflan and EMS were administered to living space (30x20x15cm aquarium and 10 liter tap water) of fish. Tap water as negative control was used. Ascorbic acid $(0.05 \%)$ was injected to the fish by intracoelomic route as $0.1 \mathrm{ml} / 10 \mathrm{~g}$ body weight at the $1^{\text {st }}$ and $3^{\text {rd }}$ days of exposures to trifluralin. The genotoxic effects of the herbicides and possible anti-genotoxic effect of ascorbic acid were evaluated using the micronucleus test and nuclear abnormality. Analysis of the results showed that applied concentrations of trifluralin, treflan and EMS increased the frequency of micronucleated cells. However, in the fish administrated ascorbic acid along with trifluralin, treflan and EMS there was a significant decrease in percentage of micronuclei as compared to trifluralin, treflan and EMS treated fish. In conclusion, ascorbic acid ameliorated the genotoxicity by the herbicides and therefore we may suggest the use of this reducing agent for the prevention of genotoxicity in fish farming.
\end{abstract}

Keywords: Antigenotoxicity, ascorbic acid, Micronucleus, Oreochromis niloticus, Trifluralin.

*e-mail: serpilkonen@gmail.com 


\section{Giriş}

Tarım alanlarında ve ürünlerde pestisitlerin yoğun kullanımı, çevreye toksik maddelerin girişine neden olabilir. Bu kimyasallar çeşitli şekillerde ırmaklara, göllere ve su kaynaklarına ulaşabilir. Sonuç olarak sucul çevrede, insanlarda ve hayvanlarda istenmeyen etkilere neden olabilir [1]. Herbisitler çeşitli ürünlerin kontrolünde kullanılan pestisit sınıflarından biridir. Trifluralin, çimlenme öncesi seçici dinitroanilin herbisittir. Bu herbisit ilk olarak Birleşmiş Milletlerde 1963 yılında kayıtlara geçmiştir. Ancak günümüzde dünyada 130'dan fazla üründe trifluralin bulunmaktadır. Trifluralin'in genotoksik etkisi, farklı test sistemleri ve genetik belirteçler kullanılarak gösterilmiştir [2, 3, 4]. Etil metan sülfonat (EMS), sadece çeşitli memeli modellerinde değil aynı zamanda bir kaç balık türünde de klastojenik, mutajenik, teratojenik ve karsinojenik etki gösterdiğinden genetik araştırmalarda pozitif kontrol olarak yoğun şekilde kullanılmaktadır [5, 6].

Çoğu epidemiyolojik ve deneysel çalışmalar, mikronutrient bakımından zengin besinlerle beslenmenin kanser ve mutasyon riskini azaltabileceğini göstermiştir [7, 8, 9, 10]. Vitaminler makromolekülleri korumada mikronutrientler olarak çok önemlidirler. En önemli mikronutrientlerden biri askorbik asit, diğer adıyla vitamin C'dir. Vitamin C birkaç metabolik reaksiyonda ileri derecede öneme sahiptir [11]. Vitamin C suda çözünebilen etkili bir antioksidandır [12]. Bir çok çalışmadan elde edilen veriler, askorbik asitin hem in vitro hem in vivo test sistemlerinde ve farklı ökaryotik dokularda [13, 14, 15, 16], insan lenfositlerinde [17, 18, 19] ve Drosophila test sistemlerinde [20] antimutajenik olduğunu göstermiştir.

Kemikli balıklar; askorbik asit sentez yolağındaki başlatıcı enzim olan gulonolakton oksidazın eksikliğinden dolayı diğer omurgalılardan farklı olarak askorbik asiti sentezleyemezler [21]. Bu nedenle, askorbik asit sucul ortamda kemikli balıklar için önemli bir bileşendir.

Balıklarda mikronukleus ve nuklear anomali testi, sucul çevrede hem ksenobiyotiklerin genotoksik etkilerinin değerlendirilmesinde hem de çeşitli kimyasalların antigenotoksik potansiyellerinin değerlendirilmesinde yoğun olarak kullanılmaktadır [22, 23, 24, 25]. Bir kaç antioksidanın farklı kimyasalların genotoksisitesini azaltıp azaltmadığına dair çalışmalar literatürde mevcuttur [26, 27, 28]. Fakat, trifluralin ve treflan'1n Oreochromis niloticus üzerindeki genotoksisitesi üzerine askorbik asitin antigenotoksik etkisi henüz çalışılmamıştır. Bu çalışmanın amacı Oreochromis niloticus’ta trifluralin, treflan ve EMS'ın oluşturduğu genotoksisite üzerine askorbik asitin antigenotoksik etkisini değerlendirmektir.

\section{Materyal ve Metot \\ Deney Hayvanı ve Kimyasallar}

Deneylerde kullanılmak üzere Oreochromis niloticus'un sağlıklı bireyleri (ortalama uzunlukta 5 $\pm 1 \mathrm{~cm}$ ve ortalama ağırlıkta $5 \pm 1 \mathrm{~g}$ ) Çukurova Üniversitesi (Adana, Türkiye) balık çiftliğinden temin edilmiştir. Deneylerden önce 80 deney hayvanı 90’ar litrelik 80x40x30cm ebatlarındaki iki akvaryuma yerleştirilmiş ve laboratuvar şartlarına alıştırılmıştır $\left(25{ }^{\circ} \mathrm{C}, 12 / 12\right.$ saat karanlık/aydınlık, 2 hafta $)$. Çalışma sırasında 30x20x15cm ebatlarındaki akvaryumlara 9 set kurularak deneyler gerçekleştirilmiştir: negatif kontrol grubu (musluk suyu), trifluralin maruziyet grubu, treflan maruziyet grubu, EMS maruziyet 
grubu, negatif kontrol (steril su enjeksiyon) grubu, askorbik asit enjeksiyon grubu, treflan + askorbik asit grubu, trifluralin + askorbik asit grubu ve EMS + askorbik asit enjeksiyon grubu.

Çalışmada aktif bileşen olarak trifluralin içeren treflan herbisiti $(480 \mathrm{~g} / \mathrm{L})$ ve \%98 saflıkta trifluralin (CAS numarası 1582-09-8) kullanılmıştır. Trifluralin, Riedel-de Haen (Seelze, Germany) firmasından temin edilmiştir. Trifluralin'in kimyasal formülü Şekil 1'de gösterilmiştir. Askorbik asit, etil metan sülfonat ve methanol Sigma firmasından satın alınmıştır. Askorbik asitin kimyasal yapısı Şekil 2’de gösterilmektedir.

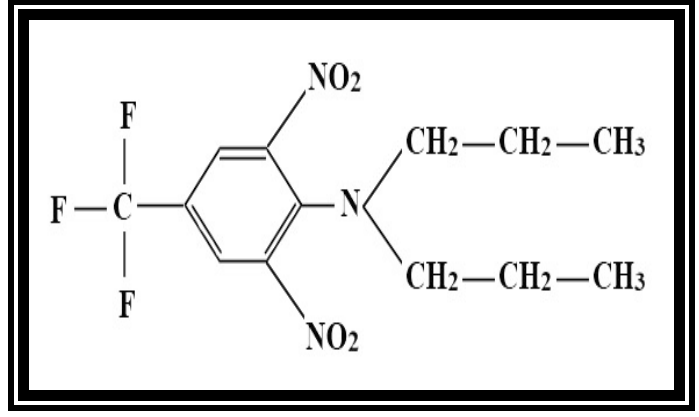

Şekil 1. Trifluralin'in kimyasal yapısı.

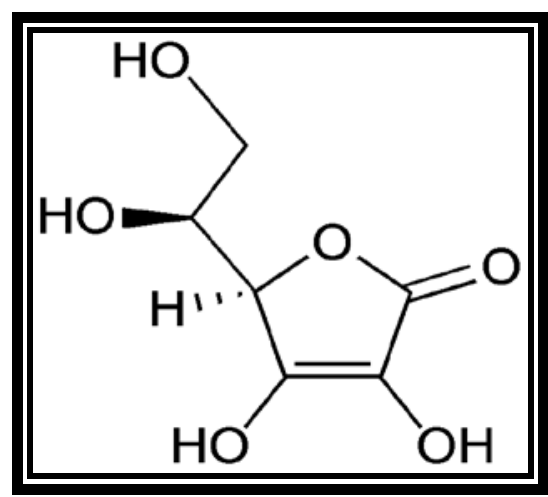

Şekil 2. Askorbik asitin kimyasal yapısı.

\section{Deney Dizaynı}

Balıklar; içerisinde $10 \mu \mathrm{g} / \mathrm{L}$ trifluralin, $10 \mu \mathrm{g} / \mathrm{L}$ treflan ve $10 \mathrm{mg} / \mathrm{L}$ EMS bulunan sularla doldurulmuş akvaryumlara yerleştirilmek suretiyle bu kimyasallara 6 gün süresince maruz bırakılmışlardır. Trifluralin ve treflan’ın genotoksik maruziyet konsantrasyonu daha önceki çalışmamızda belirlenmiştir (10 $\mu \mathrm{g} / \mathrm{L})$ [4]. Pozitif kontrol olarak EMS’nin 10 mg/L’lik konsantrasyonu kullanılmıştır. Negatif kontrol olarak musluk suyu kullanılmıştır. Maruziyet süresi sonunda Oreochromis niloticus eritrositlerinde meydana gelen hasar mikronukleus ve nuklear anomali testi ile değerlendirilmiştir. Askorbik asitin genotoksisiteyi indirgeyici etkisini belirlemek için maruziyetin 1. ve 3. günlerinde askorbik asit enjeksiyonu gerçekleştirilen ikinci bir set kurulmuştur ve maruziyet sonunda eritrositlerdeki hasarlar değerlendirilmiştir. Her test grubu için sekiz balık kullanılmıştır. Balıkların kimyasallara maruziyeti Şekil 3'te gösterildiği gibi gerçekleştirilmiştir.

\section{Mikronukleus ve Nuklear Anomali Testi}

Periferal kan örnekleri balıkların kuyruk venasından alınmış ve temiz lamlara yayılmıştır. Kurutulan lamlar 20 dakika saf etanolde fikse edilmiştir. Daha sonra lamlar hava ile kurutulmuştur. Kurutulan lamlar \%5'lik Giemsa solusyonunda 20 dakika bekletilmiş ve çekirdeklerin boyanması sağlanmıştır. Her örnekten üç preparat hazırlanmış ve her preparattan 1000 eritrositte, 100X'te sayım işlemi gerçekleştirilmiştir. Mikronukleus ve nuklear anormali değerleri ortalama 1000 hücre üzerinden değerlendirilmiştir.

\section{İstatistiksel Analiz}

Kolmogorov-Simirnov testi ile verilerin normal dağılıma uyduğu tespit edildikten sonra, farklılıkları ortaya çıkarmak için parametrik testler kullanılmıştır. Ortalama değerler arasındaki 
farkl11ıklar tek yönlü varyans analizi (ANOVA) ve Bonferroni testleri ile karşılaştırılmıştır. Tüm veriler ortalama \pm standart hata olarak verilmiştir.
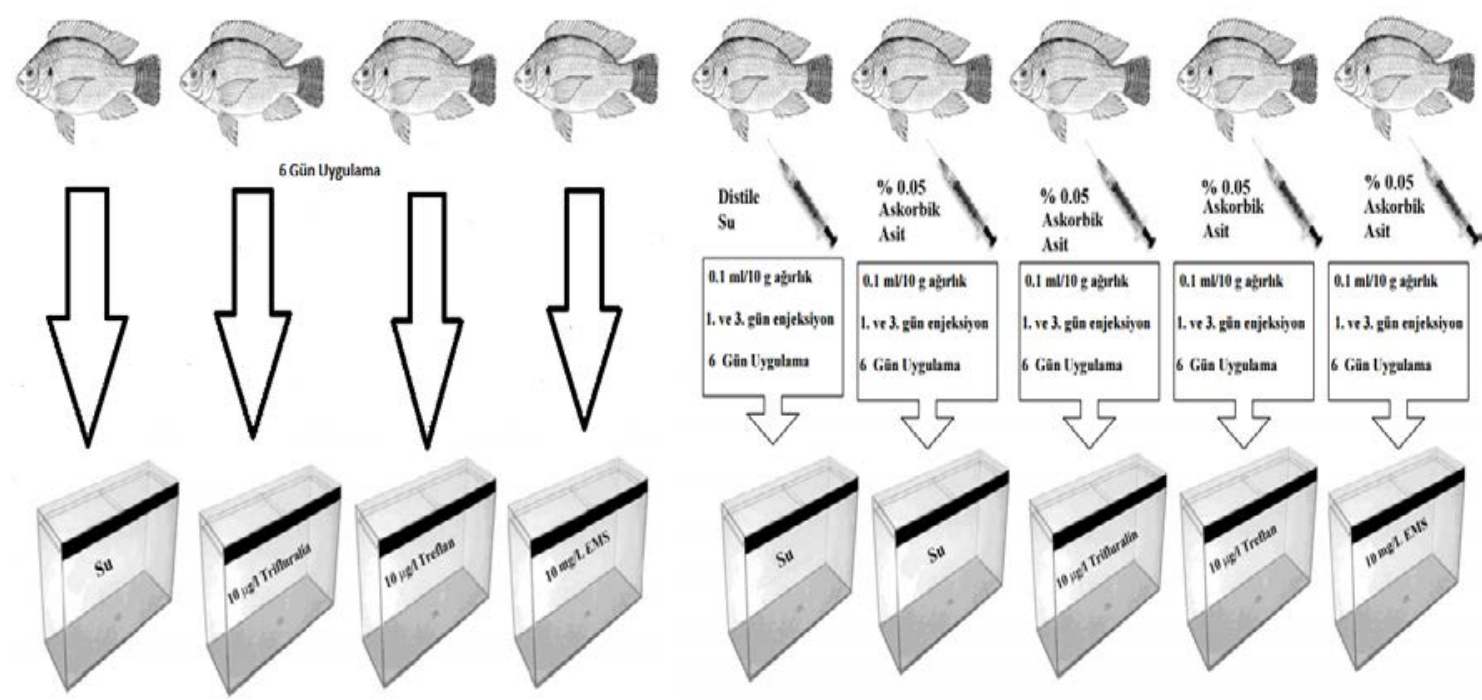

Şekil 3. Oreochromis niloticus'ların kimyasallara maruziyeti.

\section{Bulgular}

Askorbik asitin antigenotoksisite değerlendirme sonuçları Tablo 1'de gösterilmiştir. Herhangi bir kimyasala maruz bırakılmamış balıkların mikronükleus frekansı ile kimyasala maruz bırakılmamış fakat distile su enjeksiyonu yapılmış balıklardaki mikronükleus frekansı karşılaştırıldı̆̆ında önemli (anlamlı) bir farklılık tespit edilmemiştir. Herhangi bir kimyasala maruz bırakılmamış ve sadece askorbik asit enjeksiyonu yapılmış balıkların eritrositlerindeki mikronukleus sayısının kimyasala maruz bırakılmamış (su negatif kontrol) balıklardaki mikronukleus sayısından daha az olduğu gözlemlenmiştir. Trifluralin, treflan ve EMS’ye maruziyetin 1. ve 3.’üncü günlerinde askorbik asit enjeksiyonu yapılan balıkların mikronükleus frekansında, maruziyet esnasında askorbik asit enjeksiyonu yapılmamış balıkların mikronükleus frekansına göre önemli derecede azalma meydana geldiği gözlemlenmiştir.

Askorbik asit enjeksiyonu gerçekleştirilen Oreochromis niloticus eritrositlerindeki nüklear anomaliler, negatif kontrol grubundan elde edilen nüklear anomaliler (BN: Binükleus, LN: Loblu nükleus, TN: Tomurcuklu nükleus, ÇN: Çentikli nükleus) ile karşılaştırıldığında sadece binukleus $(\mathrm{P}<0.05)$ ve loblu nukleus $(\mathrm{P}<0.01)$ frekansında önemli azalma meydana gelmiştir.

Pozitif kontrol olarak uygulanan etil metan sülfonat tek başına güçlü bir genotoksik ajan olarak etki göstermesine rağmen, askorbik asit ile kombine bir şekilde uygulandığında mikronukleus sıklığında \%57,89 oranında azalma meydana gelmiştir. Askorbik asitin etkisiyle mikronukleus sıklığ $1 \%$ 19,33’den \%o8,66’ya düşmüştür $(\mathrm{P}<0.001)$.

$10 \mu \mathrm{g} / \mathrm{L}$ 'lik trifluralin dozuna maruziyet sonrasında Oreochromis niloticus eritrositlerindeki mikronukleus frekansı artmıştır ve kullanılan trifluralin dozu genotoksik bulunmuştur. Fakat, askorbik asit ve trifluralin birlikte maruz bırakılan balıkların eritrositlerindeki mikronukleus frekansı ve nüklear anomali değerleri negatif kontrole yakın çıkmıştır. Askorbik asit mikronukleus oranını \%o7,66’ya düşürmüştür. 
Oreochromis niloticus eritrositlerindeki mikronukleus sıklığı trifluralin’in ticari formu olan treflan maruziyeti sonucunda da kontrol grubuyla karşılaştırıldığında önemli oranda yükselmiştir. Bu durumun aksine, treflan askorbik asitle birlikte uygulandığında mikronukleus frekansında azalma meydana gelmiştir ve genotoksisite oranı negatif kontrole yakın bulunmuştur. Askorbik asit genotoksisiteyi \%o8,37’ye düşürmüştür. Askorbik asitle birlikte gerçekleştirilen maruziyetlerde elde edilen sonuçlar; askorbik asitin Oreochromis niloticus eritrostlerinde genotoksik etki gösteren trifluralin, treflan ve etil metan sülfonat'ın oluşturduğu genotoksik etkiyi azalttığını göstermiştir. Şekil 4'te maruziyet sonrası Oreochromis niloticus eritrositlerinde oluşan mikronukleus ve nüklear anomali görüntüleri verilmiştir.

Tablo 1. Oreochromis niloticus örneklerinde askorbik asit (AA), trifluralin, treflan ve EMS uygulamalarıyla oluşan mikronükleus ve nükleus düzensizlik frekansları.

\begin{tabular}{|c|c|c|c|c|c|}
\hline \multirow{2}{*}{ Deney Grupları } & \multicolumn{2}{|l|}{ Mikronükleus } & \multicolumn{3}{|c|}{ Nükleus Düzensizlik Frekansları (\%) } \\
\hline & Frekansları (\%o) & BN & $\mathbf{L N}$ & $\mathbf{T N}$ & ÇN \\
\hline Su (Negatif Kontrol) & $3.23 \pm 0.72$ & $3.80 \pm 1.12$ & $1.40 \pm 0.13$ & $0.26 \pm 0.11$ & $1.60 \pm 0.16$ \\
\hline Su Enjekte & $3.33 \pm 0.35$ & $2.16 \pm 0.27$ & $0.87 \pm 0.22$ & $0.50 \pm 0.12$ & $1.45 \pm 0.24$ \\
\hline AA Enjekte & $2.54 \pm 0.37$ & $0.20 \pm 0.24^{b}$ & $0.79 \pm 0.24^{\mathrm{a}}$ & $0.66 \pm 0.10$ & $1.16 \pm 0.17$ \\
\hline EMS & $19.33 \pm 1.90$ & $10.20 \pm 1.78$ & $10.60 \pm 1.76$ & $2.66 \pm 0.30$ & $26.26 \pm 1.33$ \\
\hline EMS+AA & $8.66 \pm 0.98 * * *$ & $1.00 \pm 0.28 * * *$ & $2.04 \pm 0.46^{* * *}$ & $1.60 \pm 0.25^{* * *}$ & $14.37 \pm 1.05^{* * *}$ \\
\hline Trifluralin & $24.00 \pm 3.36$ & $5.93 \pm 1.24$ & $9.80 \pm 1.88$ & $3.40 \pm 0.51$ & $32.60 \pm 1.82$ \\
\hline Trifluralin + AA & $7.66 \pm 1.23^{* * *}$ & $1.16 \pm 0.38 * *$ & $2.66 \pm 0.36 * *$ & $1.05 \pm 0.14^{* *}$ & $15.75 \pm 1.36^{* * *}$ \\
\hline Treflan & $13.93 \pm 1.39$ & $7.80 \pm 2.01$ & $5.06 \pm 0.68$ & $2.20 \pm 0.87$ & $22.06 \pm 1.45$ \\
\hline Treflan + AA & $8.37 \pm 0.80 * *$ & $1.04 \pm 0.22^{* *}$ & $1.25 \pm 0.24^{* *}$ & $1.74 \pm 0.15^{*}$ & $18.54 \pm 1.21 *$ \\
\hline
\end{tabular}

\section{Tartışma ve Sonuç}

Ksenobiyotikler ve çevresel kirleticiler gibi birçok kirletici çevrede bulunmaktadır. Pestisitler en önemli ksenobiyotiklerden biridir. Tüm canlıların çevresel kontaminasyonlar nedeniyle pestisitlere maruziyeti kaçınılmazdır. Pestisit maruziyeti embriyotoksisite, genotoksisite, teratojenite ve doku hasarına neden olabilir [1, 29, 30, 31, 32, 33]. Canlılarda bu etkilerin ortaya çıkmasında pestisitlerin ürettiği reaktif oksijen türlerinin etkili olduğu düşünülmektedir. Çalışmalar reaktif oksijen türlerinin hem endojen hem de eksojen uyarıcılar sonucu üretildiğini göstermektedir [34]. Güçlü deliller, antioksidanların reaktif oksijen türleri tarafından üretilen DNA hasarlarını azaltabileceğini göstermiştir [34, 35, 36].

Askorbik asit veya diğer adıyla vitamin $\mathrm{C}$ hem in vivo hem de in vitro sistemlerde antigenotoksik özelliği yaygın olarak çalışılan antioksidanlardan biridir [37, 38, 39, 40]. Son yıllarda gerçekleştirilen çeşitli çalışmalarda askorbik asitin antigenotoksik özelliği değerlendirilmiştir. Longchar ve Prasad [41], tümör taşıyan farelerde cisplatinin neden olduğu hematotoksisiteyi azaltmak için çalışmalarında askorbik asiti kullanmışlardır. Cisplatin uygulamasının tek başına kan hücrelerinin sayısında azalma ve 
morfolojisinde değişikliklere neden olduğunu, askorbik asitle kombine şekilde kullanıldığında ise kan hücre sayısında artma ve morfolojideki değişikliklerin düzelmesine neden olduğunu gözlemlemişlerdir. Premkumar ve Bowlus [13], askorbik asitin farelerde in vivo demir genotoksisitesini engellediğini göstermiş̧lerdir. Ek olarak, Ahmad ve ark., [17] insan lenfosit kültüründe hidrokortizonun neden olduğu genotoksisite üzerine karotenoid, kurkumin, askorbik asit ve flavonoid'in antigenotoksik etkisini kromozomal aberasyon, kardeş kromatit değişimi tekniklerini kullanarak çalışmışlardır. Araştırma sonuçları, askorbik asit ve kurkuminin yüksek derecede antigenotoksik özelliğe sahip olduğunu göstermiştir. Diğer yandan Surjyo ve Anisur [42] çalışmalarında \%1'lik askorbik asitin farelerde p-DAB ve PB gibi tümorojenik ve klastojeniklere karşı koruyucu etkisini değerlendirmişlerdir. Askorbik asitin antigenotoksik özelliğe sahip olduğuna dair benzer sonuçlar Kaya ve ark., [43] tarafindan da bulunmuştur.

Antioksidanlar kimyasallar tarafindan neden olunan mutasyonları farklı şekillerde azaltabilirler. Bunlardan ilki; elektrofilik mutajenler için DNA üzerindeki nükleofilik alanlara bağlanmadır. İkincisi oksidasyon proseslerini bloklayarak promutajen biyoaktivasyonunun inhibisyonudur. Son olarak ise promutajenin elektrofilik metabolitleri ile reaksiyon sonucu mutasyonları azaltabilirler [44]. Kaya ve ark., [10] çalışmalarında askorbik asitin koruyucu etkisini ilk mekanizmaya göre gösterdiğini belirtmişlerdir.

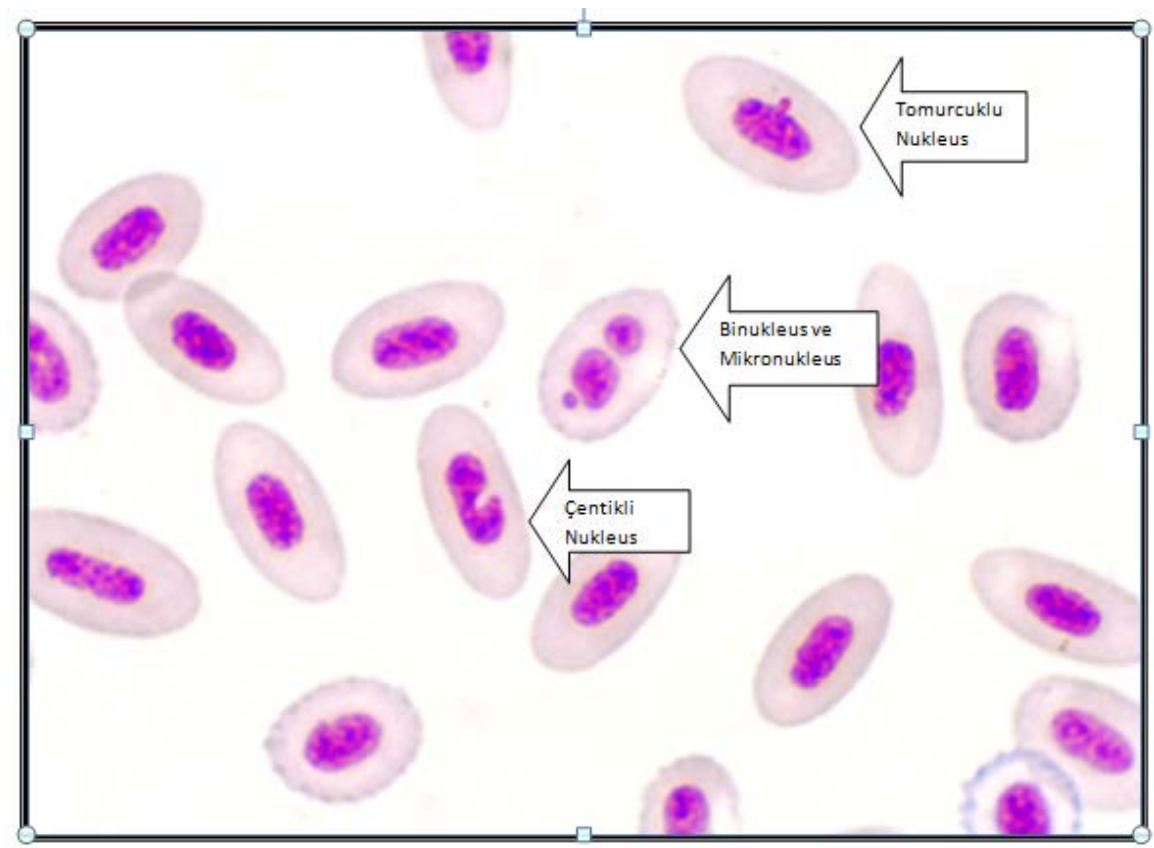

Şekil 4. Trifluralin'e maruz bırakılan Oreochromis niloticus örneklerinde mikronükleus ve nükleus düzensizlikleri.

Balıklar askorbik asit sentezleyemez ve sonuç olarak askorbik asit balık besinlerinin önemli bileşenlerinden biridir [45]. Fakat balıklarda antigenotoksisite çalışması sınırlı sayıdadır. Guha ve ark., [46] vitamin $C$ ve $\beta$-karotenin antigenotoksik etkisini mikronukleus testi, kromozom aberasyon testi, nukleus anomalisi ve sperm baş anomalisi testini kullanarak endemik balık Anabas testudineus'ta çalışmışlardır. Ek olarak, Guha ve Khuda-Bukhsh [6] Oreochromis mossambicus'da EMS'nin genotoksik potansiyelini göstermiş ve askorbik asitin genotoksik hasarı düzenleyici etkisini kromozom aberasyon testi, nüklear anomali testi ve çeşitli dokuların protein sentezindeki değişikliklere göre 
değerlendirmişlerdir. Benzer çalışmalar Jiraungkoorskul ve ark., tarafından da gerçekleştirilmiştir [47]. Kumar bir çalışmasında kadmiyumun neden olduğu oksidatif stresin azaltılmasında askorbik asit maruziyetinin düzenleyici etkisini göstermiştir [25]. Bu çalışmada ticari öneme sahip balık türü olan, Oreochromis niloticus'da askorbik asitin antigenotoksik potansiyeli belirlenmiştir. Ayrıca, Oreochromis niloticus'un benzer antigenotoksisite çalışmalarında model organizma olarak kullanılabileceği de tespit edilmiştir.

Antigenotoksisite değerlendirmeleri için geniş kullanım alanına sahip bir herbisit trifluralin ve onun ticari formu treflan ile birlikte genotoksik olduğu iyi bilinen EMS kullanılmıştır. Akut genotoksisite verileri teknik trifluralinin Oreochromis niloticus eritrositlerinde daha genotoksik olduğunu göstermiştir. Trifluralin, Çevre Koruma Ajansı (Environmental Protection Agency; EPA) tarafından muhtemel insan karsinojeni (Grup C) olarak sınıflandırılmıştır. Ayrıca; trifluralin, treflan ve EMS’nin genotoksik etkileri daha önce gerçekleştirdiğimiz çalışmada değerlendirilmiştir [4].

Vitaminlerin antigenotoksisitesi ile ilgili araştırmalar vardır ancak balıklarda antigenotoksisite çalışması sınırlıdır. Çalışmamızda askorbik asitin antigenotoksik olup olmadığı değerlendirilmiştir. Sonuçlar, askorbik asitin trifluralinin, treflan ve EMS'nin genotoksik etkisini sırasıyla \%70,83, \%42,85 ve \%57,89 azalttığını göstermiştir. Askorbik asit balıklar için önemli bir bileşendir ve balıklar günlük beslenmede almak zorundadır. Sonuç olarak askorbik asit, toksik kimyasalların genotoksik etkisini azaltma yeteneğine sahiptir.

\section{Teşekkür}

Bu çalışma Mersin Üniversitesi Bilimsel Araştırma Proje ekibi tarafından desteklenmiştir. (Proje Kodu: BAP-FBE BB (SK) 2006-1 YL).

\section{Kaynaklar}

[1] Fetoui H., Makni M., Garoui E.M., Zeghal N., "Toxic effects of lambda-cyhalothrin, a synthetic pyrethroid pesticide, on the rat kidney: Involvement of oxidative stress and protective role of ascorbic acid” Experimental and Toxicologic Pathology, 62, 593-599, 2010

[2] Ghiazza G., Zavarise G., Lanero M., Ferraro G., "Sister chromatid exchanges induced in human lymphocyte chromosomes by trifluralin, atrazine and simazine” Bollettino Della Societa Italiana di Biologia Sperimentale, 11, 2149-2153, 1984

[3] Pilinskaia M.A., “ Evaluation of the cytogenetic effect of the herbicide treflan and of a number of its metabolites on mammalian somatic cells” Tsitologia Genetica, 21(2), 131-5, 1987

[4] Könen S., Cavas T., " Genotoxicity testing of the herbicide trifluralin and its commercial formulation Treflan using the piscine micronucleus test" Environmental Molecular Mutagenesis, 49, 434-438, 2008

[5] Hooftman R.N., "The induction of chromosome-aberrations in Notobranchius rachowi (Pisces, Cypridontidae) after treatment with ethyl methane sulfonate or benzo[a]pyrene” Mutation Research , 91(4- 5), 347-352, 1981

[6] Guha B., Khuda-Bukhsh A.R., “ Efficacy of vitamin-C (L-ascorbic acid) in reducing genotoxicity in fish (Oreochromis mossambicus) induced by ethyl methane sulphonate” Chemosphere, 47, 49-56, 2002 
[7] Ames B., “ Dietary carcinogens and anticarcinogens” Science, 221, 1256-63, 1983

[8] Block G., "Vitamin C and cancer prevention: The epidemiologicalevidence” American Journa of Clinical Nutrition, 53, 270-80, 1991

[9] Byers T., Perry G., “ Dietary carotenes, vitamin C and vitamin E as protective antioxidant in human cancer” Annual Review of Nutrition, 12, 139-59, 1992

[10] Kaya B., “ Antigenotoxic effect of Ascorbic acid on mutagenic dose of three alkylating agents” Turk Journal Biology, 27, 241-46, 2003

[11] Halliwell B., “Vitamin C and genotoxic stability” Mutation Research, 475, 29-35, 2001

[12] Frei B., England L., Ames B.N., “Ascorbate is an outstanding antioxidant in human blood plasma” Proceedings of the National Academy of Sciences of the United States of America, 86, 6377-6381, 1989

[13] Premkumar K., Bowlus C.L., “Ascorbic acid reduces the frequency of iron induced micronuclei in bone marrow cells of mice” Mutation Research, 542(1-2), 99-103, 2003

[14] Ozturk I.C., Ozturk F, Gul M., Ates B., Cetin A., “ Protective effects of ascorbic acid on hepatotoxicity and oxidative stress caused by carbon tetra chloride in the liver of Wistar rats” Cell Biochemistry and Function, 27, 309-315, 2009

[15] Rajesh P., Sathish S., Srinivasan C., Selvaraj J., Balasubramanian K., "Phthalate is Associated With Insulin Resistance in Adipose Tissue of Male Rat:Role of Antioxidant Vitamins” Journal of Cellular Biochemistry, 114 , 558-569, 2013

[16] Uzun F.G., Kalender S., Durak D., Demir F., Kalender Y., “ Malathion-induced testicular toxicity in male rats and the protective effect of vitamins C and E” Food and Chemical Toxicology, 47, 1903-1908, 2009

[17] Ahmad M.S., Afzal M., “Amelioration of genotoxic damage by certain phytoproducts in human lymphocyte cultures” Chemico-Biological Interactions, 149(2-3), 107-15, 2004

[18] Turkez H., “ The role of ascorbic acid on titanium dioxide-induced genetic damage assessed by the comet assay and cytogenetic tests” Experimental andToxicologic Pathology, 63, 453-457, 2011

[19] Turkez H., Aydın E., “ The protective role of ascorbic acid on imazalil-induced genetic damage assessed by the cytogenetic tests” Toxicology and Industrial Health, 28(7), 648-654, 2012

[20] Kaya B., Creus A., Velazquez A., Yanıkoğlu A., Marcos R., “ Genotoxicity is modulated by ascorbic acid Studies using the wing spot test in Drosophila” Mutation Research, 520, 93-101, 2002

[21] Ciereszko A., Dabrowski K., Lin F., Liu L., "Protective role of ascorbic acid against damage to male germ cells in rainbow trout (Oncorhynchus mykiss)” Canadian Journal Of Fisheries And Aquatic Sciences, 56(2), 178-183, 1999

[22] Çavaş T., Könen S., "In vivo genotoxicity testing of the amnesic shellfish poison (domoic acid) in piscine erythrocytes using the micronucleus test and the comet assay” Aquatic Toxicology, 90, 154-159, 2008 
[23] Çavaş T., Könen S., “ Detection of cytogenetic and DNA damage in peripheral erythrocytes of goldfish (Carassius auratus) exposed to a glyphosate formulation using the micronucleus test and the comet assay” Mutagenesis, 22 (4), 263-268, 2007

[24] Çavaş T., "In vivo genotoxicity evaluation of atrazine and atrazine-based herbicide on fish Carassius auratus using the micronucleus test and the comet assay” Food And Chemical Toxicology, 49(6), 1431-1435, 2011

[25] Kumar P., Prasad Y., Patra A.K., Ranjan R., Swarup D., Patra R.C., Pal S., “Ascorbic acid, garlic extract and taurine alleviate cadmium-induced oxidative stres in freshwater catfish (Clarias batrachus)” Science of the Total Environment, 407, 5024-5030, 2009

[26] Mastrangelo S., Tomassetti M., Carratu M.R., Evandri M.G., Bolle P., "Quercetin reduces chromosome aberrations induced by atrazine in the Allium cepa test” Environmental And Molecular Mutagenesis, 47(4), 254-259, 2006

[27] Demir E., Kocaoglu S., Cetin H., Kaya B., “Antigenotoxic Effects of Citrus aurentium L. Fruit Peel Oil on Mutagenicity of Two Alkylating Agents and Two Metals in the Drosophila Wing Spot Test” Environmental And Molecular Mutagenesis, 50(6), 483-488, 2009

[28] Siddique Y.H., Ara G., Gupta J., Beg T., Afzal M., "Protective Effect of Curcumin against Hydrogen Peroxide Induced Genotoxic Damage in Cultured Human Lymphocytes” Research Journal Of Biotechnology, 390-392, 2008

[29] Paskova V., Hilscherova K., Blaha L., “Teratogenicity and embryotoxicity in aquatic organisms after pesticide exposure and the role of oxidative stress" Reviews of Environmental Contamination and Toxicology, 211, 25-61, 2011

[30] Sinha S., Panneerselvam N., Shanmugam G., “ Fluchloralin is cytotoxic and genotoxic and induces apoptosis in mammalian cells” Environmental Molecular Mutagenesis, 31, 257-62, 1998

[31] Çavaş T., Ergene-Gozukara S., "Evaluation of the genotoxic potential of lambda-cyhalothrin using nuclear and nucleolar biomarkers on fishcells” Mutation Research, 534, 93-9, 2003

[32] Soni I., Bhatnagar P., "Embryotoxic and teratogenic studies of phosphamidon in Swiss albino mice” Teratogen Carcinogen Mutagen, 9, 253-7, 2005

[33] Tisch M., Faulde M.K., Maier H., "Genotoxic effects of penta chloro phenol, lindane, transfluthrin, cyfluthrin, and natural pyrethrum on human mucosal cells of the inferior and middle nasal conchae” American Journal of Rhinology, 19, 141-51, 2005

[34] Fuchs-Tarlovsky V., "Role of antioxidants in cancer therapy” Nutrition, 29, 15-21, 2013

[35] Banerjee P., Bhattacharyya S.S., Bhattacharjee N., Pathak S., Boujedaini N., Belon P.A., Khuda-Bukhsh A.R., “Ascorbic acid combats arsenic-induced oxidative stress in mice liver" Ecotoxicology and Environmental Safety, 72, 639-649, 2009

[36] Chandrasekharan D.K., Kagıya T.V., Nair C.K.K., "Radiation Protection By 6-Palmitoyl Ascorbic Acid-2 Glucoside:Studies On DNA Damage In Vitro, Ex Vivo, In Vivo and Oxidative Stress In Vivo” Journal of Radiation Research, 50, 203-212, 2009

[37] Zuniga-Gonzalez G.M., Gomez-Meda B.C., Zamora-Perez A.L., Martinez-Gonzalez M.A., Haro I.A.M., Perez-Navarro A.E., Armendariz-Borunda J., Gallegos-Arreola M.P., “Micronucleated erythrocytes in newborns of rat dams exposed to ultraviolet-A light during pregnancy; protection 
by ascorbic acid supplementation” Mutation Research/Genetic Toxicology and Environmental Mutagenesis, 782, 36-41, 2015

[38] Johnson A.A., Naaldijk Y., Hohaus C., Meisel H.J., Krystel I., Stolzing A., "Protective effects of alpha phenyl-tert-butyl nitrone and ascorbic acid in human adipose derived mesenchymal stem cells from differently aged donors” Aging, 8, 1-13, 2016

[39] Roy P., Mukherjee A., Giri S., "Positive effects of Vitamin C in arsenic trioxide and sodium fluoride induced genotoxicity and oxidative stres in mice in vivo” Pollution, 1(4), 451-460, 2015

[40] Hassan K.A., Ahmed M.A., Hassanein K.M.A., Waly H., “Ameliorating effect of vitamin C and selenium against nicotine induced oxidative stress and changes of p53 expression in pregnant albino rats”, Journal of Advanced Veterinary and Animal Research, 3(4), 2016

[41] Longchar A., Prasad S.B., "Ascorbic acid (Vitamin C)ameliorates cisplatin-induced hematotoxicity in tumor-bearing mice” World Journal of Pharmacy and Pharmaceutical Sciences, 5(4), 1870-1891, 2016

[42] Surjyo B., Anisur K.B., "Protective action of an anti-oxidant (L-Ascorbic acid) against genotoxicity and cytotoxicity in mice during p-DAB-induced hepatocarcinogenesis” Indian Journal of Cancer, 41(2), 72- 80, 2004

[43] Kaya B., Marcos R., Yanikoglu A., Creus A., "Evaluation of the genotoxicity of four herbicides in the wing spot test of Drosophila melanogaster using two different strains" Mutation Research, 557(1), 53-62, 2004

[44] Goncharova R.I., Kuzhir T.D., “A comparative study of the antimutagenic effects of antioxidants on chemical mutagenesis in Drosophila melanogaster” Mutation Research, 214, 257-265, 1989

[45] Aksoy A., Çeliköz B., Dedebali N., Emre N., Ertekin H., Fedakar D., Kocakaya S., Kurtoğlu A., Maekawa A., Mefut A., Nezaki G., Oikawa M., Öztürk E., Sevgili H., Sümer Ç., Süyek R., Takeno N., Tekşam I, Udagawa K., Wakita K., “Kalkan (Psetta maxima) Yetiştiriciliği” EI Kitabı Özel yayın 1, Aralık, 2010.

[46] Guha B., Das J.K., Khuda-Bukhsh A.R., “Ameliorative effects of vitamin supplementation on ethyl methane sulphonate-induced genotoxicity in a fish, Anabas testudineus” Ecotoxicology and Environmental Safety, 68, 63-70, 2007

[47] Jiraungkoorskul W., Shaphong S., Kosai P., Kim M.H., "Micronucleus Test: The Effect of AscorbicAcid on Cadmium Exposure in fish (Puntius altus)" Research Journal of Environmental Toxicology, 1(1), 27-36, 2007 